\title{
CRESCIMENTO DE MUDAS DE BARU E GONÇALO-ALVES EM SOLO DEGRADADO, SUPLEMENTADO COM RESÍDUO, EM ILHA SOLTEIRA - SP
}

\author{
GROWTH OF BARU AND GONÇALO-ALVES SEEDLINGS IN DEGRADED SOIL, \\ SUPPLEMENTED WITH RESIDUE IN ILHA SOLTEIRA-SP STATE
}

\author{
Kellian Kenji Gonzaga da Silva Mizobata ${ }^{1}$ Ana Maria Rodrigues Cassiolato ${ }^{2}$ \\ Kátia Luciene Maltoni ${ }^{3}$
}

\begin{abstract}
RESUMO
O processo de revegetação representa uma alternativa para recuperação de áreas com solo exposto. Este trabalho objetivou avaliar o crescimento de mudas de Dipteryx alata (baru) e Astronium fraxinifolium (gonçalo-alves) em solo degradado, compactado ou não, suplementado com resíduo agroindustrial e verificar a possibilidade de uso deste como condicionante do solo. O experimento, conduzido na UNESP/Campus de Ilha Solteira, em cultivo protegido, apresenta três doses de resíduo $\left(0,15\right.$ e $\left.30 \mathrm{t} \mathrm{ha}^{-1}\right)$, duas densidades $\left(1,0\right.$ e 1,5 $\left.\mathrm{g} \mathrm{cm}^{-3}\right)$ e duas plantas indicadoras (Dipteryx alata e Astronium fraxinifolium). As plantas, arbóreas de cerrado, ocorrem nas proximidades da área degradada, onde o solo foi coletado. As mudas foram avaliadas 7 meses após desbaste, para altura, diâmetro do caule, número de folhas, massa fresca e seca da parte aérea e do sistema radicular, e o solo foi avaliado para análise da fertilidade. Os resultados mostram que o resíduo agroindustrial (RA) elevou $\mathrm{pH}$, teores de potássio, cálcio e magnésio, e diminuiu o alumínio disponível. O Dipteryx alata teve a massa fresca da raiz influenciada negativamente pela compactação e se mostrou pouco exigente quanto à adição de nutrientes pelo RA. O Astronium fraxinifolium teve a massa fresca da raiz e a altura negativamente influenciados pela compactação, enquanto a adição do RA favoreceu altura, diâmetro do caule, massa fresca e seca da parte aérea e do sistema radicular. A morfologia das raízes foi alterada pela compactação, nas duas espécies. O substrato utilizado apresenta elevada capacidade de reorganização, produzindo elevada densidade sem aplicação de força.
\end{abstract}

Palavras-chave: Cerrado; cinza do bagaço da cana-de-açúcar; fertilidade do solo.

\begin{abstract}
The revegetation process represents an alternative to recovery of areas with exposed soil. The aim of this research was evaluate the growth of Dipteryx alata (baru) and Astronium fraxinifolium (gonçalo-alves) seedlings in degraded soil, compacted and not, supplemented with agro-industrial residue, and verify the possibility of using this as a chemical soil conditioner. The experiment was conducted at UNESP/Ilha Solteira Campus, under protected cultivation, with the following treatments: 3 doses of residue $\left(0,15\right.$ and $\left.30 \mathrm{t} \mathrm{ha}^{-1}\right)$, two densities $\left(1.0\right.$ and $\left.1.5 \mathrm{~g} \mathrm{~cm}^{-3}\right)$ and two indicator plants (Dipteryx alata e Astronium fraxinifolium). The selected plants are arboreal species from 'cerrado' biome, which occur in the vicinity of the degraded area, where the soil was

1 Bióloga, Mestranda do Programa de Pós-Graduação em Agronomia, Faculdade de Engenharia, Universidade Estadual Paulista, Av. Brasil, 56, Centro, CEP 15385-000, Ilha Solteira (SP), Brasil. kelliankenji@gmail.com

2 Bióloga, Dr ${ }^{\mathrm{a}}$., Professora Assistente da Universidade Estadual Paulista, Av. Brasil, 56, Centro, CEP 15385-000, Ilha Solteira (SP), Brasil. anamaria@bio.feis.unesp.br

3 Engenheira Agrimensora, Dr ${ }^{\mathrm{a}}$., Professora Assistente da Universidade Estadual Paulista, Av. Brasil, 56, Centro, CEP 15385-000, Ilha Solteira (SP), Brasil. maltoni@agr.feis.unesp.br
\end{abstract}

Recebido para publicação em 9/02/2013 e aceito em 20/08/2015 
collected. The seedlings were evaluated 7 months after roughing, for height, diameter of stem, number of leaves, fresh and dry weight of shoots and roots, and the soil was evaluated for fertility. The results show that the agro-industrial residue (RA) has increased the $\mathrm{pH}$, potassium, calcium and magnesium, and reduced the exchangeable aluminum. The Dipteryx alata fresh root weight, was negatively influenced by compaction and showed little demanding for nutrients added by RA. Fresh root weight and height of Astronium fraxinifolium were negatively influenced by compaction whereas the addition of agro-industrial residue increased the plant height, stem diameter, fresh and dry weight of shoot and root. The root morphology was affected by compaction, in both species. The used substrate presents a high capacity of particles reorganization, resulting in a high density, without force application.

Keywords: Cerrado biome; Sugar-cane bagasse ash (SCBA); soil fertility.

\section{INTRODUÇ̃̃O}

O uso da cobertura vegetal, como medida mitigadora de impacto ambiental, pode ser uma opção prática, econômica e coerente (VALCARCEL; D' ALTERIO, 1998). Área degradada é aquela que sofreu alterações em suas características originais, em decorrência de causas naturais ou oriundas de ação antrópica. Em algumas dessas áreas ocorre a eliminação do meio biótico e estas passam a apresentar baixa resiliência (ENGEL; PARROTA, 2003; CORREAA, 2005; CRESTANA et al., 2006; MIKOLA et al., 2014).

A partir de 1960, com a interiorização da capital brasileira, a implantação de infraestruturas viária e energética, o incremento de atividades agrárias rentáveis e os incentivos do governo para a expansão da agropecuária no cerrado, que até então era pouco explorado, resultou em um ambiente intensamente degradado (VASCONCELOS; SANTOS, 2003; SOUSA-SILVA; FAGG, 2011). Mais recentemente, na região, surge uma demanda dos setores industriais, aumentando ainda mais a pressão sobre o Bioma

Em 1965, teve início a construção da Usina Hidrelétrica de Ilha Solteira (COMPANHIA ENERGÉTICA DE SÃO PAULO, 1988), no Noroeste do Estado de São Paulo, divisa com Mato Grosso do Sul, produzindo extensas áreas degradadas (áreas de empréstimo, com remoção dos horizontes superficiais do solo). Estes locais apresentam, ainda hoje, insignificante regeneração natural, mesmo dentro do bioma Cerrado, fato corroborado por Durigan (1999), quando explica que, em condições de terraplanagem e cortes, o cerrado apresenta médio ou lento potencial de regeneração natural.

Dentre os principais problemas edáficos encontrados em áreas de empréstimos ou mineradas, com exposição dos horizontes subsuperficiais do solo, estão a falta de agregação, a compactação, as baixas taxas de infiltração, a alta resistência à penetração de raízes, a presença de acentuado processo erosivo, entre outros. Estes fatores, associados à quase total ausência de matéria orgânica e à baixa disponibilidade de nutrientes, não permitem o adequado estabelecimento da vegetação (MOREIRA, 2004; RODRIGUES et al., 2007; AN et al., 2013). No cerrado, estes problemas se apresentam associados à baixa fertilidade natural do solo e ao demarcado regime pluviométrico (CORREIA et al., 2002; RESENDE et al., 2002).

A revegetação de áreas degradadas a partir da introdução de espécies nativas pode trazer vantagens, pois estas já estão adaptadas às condições ambientais presentes e terão uma maior chance de sobrevivência (MELO et al., 1998). De acordo com Ruivo (1993), a reimplantação da vegetação possibilita a produção de matéria orgânica, bem como a recuperação da comunidade microbiana do solo, mas para o estabelecimento da vegetação, em solos degradados de cerrado, é necessária a utilização de insumos químicos e orgânicos (LEITE et al., 1994). 
Toneladas de resíduos, industriais e agrícolas, são geradas no processo de transformação de matérias-primas. A maioria destes resíduos não possui aplicação específica e pode gerar problemas ambientais, devido a sua disposição desordenada. Existe, atualmente, uma forte demanda pela regulamentação da disposição destes resíduos. Como consequência, nos últimos anos, tem-se verificado um crescente número de trabalhos voltados à utilização e ao aproveitamento de resíduos industriais e agrícolas, quer seja na produção de materiais voltados para o setor da construção civil (CORDEIRO et al., 2009; MODANIA; VYAWAHAREB, 2013), quer seja como insumos agrícolas (FEITOSA et al., 2009; PITA, 2009; THIND et al., 2012), entre outros.

A região Noroeste do Estado de São Paulo e seu entorno tem assumido lugar de destaque em termos agroindustriais, devido à implantação de várias usinas do setor sucroalcooleiro. Estas, ao mesmo tempo vem se convertendo em grande produtora de cana-de-açúcar e, consequentemente, de açúcar, álcool e resíduos, como bagaço, palha da cana e cinza do bagaço (FREITAS, 2005). Para cada tonelada de cana-de-açúcar beneficiada são gerados cerca de $250 \mathrm{~kg}$ de bagaço e 6,0 kg de cinza (FEDERAÇÃO DAS INDÚSTRIAS DO ESTADO DE SÃO PAULO, 2001; ROMERO, 2007; CORDEIRO et al., 2009), ou seja, milhões de toneladas de cinza produzidas ao longo do ano.

O destino corrente de milhões de toneladas de cinza tem sido o solo, no qual estas vêm sendo aplicadas sem nenhuma preocupação ou estudo prévio (FREITAS, 2005).

A utilização da cinza como insumo no processo produtivo agrícola é ambiental e economicamente viável, pois o material possibilita alta capacidade de retenção de água, melhora o desenvolvimento da cultura e reduz impactos ambientais provocados pela irrigação, além de ser fonte de macro e micronutrientes. Esta tem capacidade para corrigir a acidez do solo, de tal modo que uma tonelada de cinza equivale a 0,5 tonelada de calcário (BRUNELLI; PISANI JUNIOR, 2006).

Várias espécies arbóreas de Cerrado vêm sendo valorizadas comercialmente, entre estas o Dipteryx alata Schott (baru), leguminosa que produz frutos com polpa carnosa durante a estação seca e se destaca como espécie importante para alimentação da fauna nessa época. O uso do baru em áreas a serem recuperadas, como reservas legais e de proteção ambiental, favorecerá sua conservação e contribuirá para manutenção de espécies associadas (RIBEIRO et al., 2000; SANO; RIBEIRO; BRITO, 2004).

O Astronium fraxinifolium Vog. (gonçalo-alves) é outra espécie de Cerrado, da família Anacardiaceae, de grande importância econômica, pois produz madeira de excelente qualidade (madeira de lei), muito usada na construção civil e naval, ou ainda para uso medicinal. Apresenta um desenvolvimento rápido, chegando a atingir três metros aos dois anos de idade, é ecologicamente classificada como agressiva e resistente a condições adversas (LORENZI, 1992; AGUIAR et al., 2001).

Dentro deste contexto propôs-se avaliar, em ambiente controlado, o crescimento de mudas de baru e gonçalo-alves (arbóreas de cerrado) em solo de cerrado degradado, compactado e não compactado, utilizando resíduo agroindustrial como condicionante do solo.

\section{MATERIAL E MÉTODOS}

O experimento, conduzido na UNESP-Universidade Estadual Paulista, Campus de Ilha Solteira, teve o material de solo coletado em área degradada na década de 60, pela construção da Usina Hidrelétrica de Ilha Solteira (SP), de onde foram removidos os horizontes superficiais do solo, com cortes que atingiram espessuras em torno de $10 \mathrm{~m}$, e até hoje permanece exposto, devido à baixa regeneração natural no local. 
O solo foi coletado na camada de 0,00 a $0,20 \mathrm{~m}$ e peneirado (malha de $4 \mathrm{~mm}$ ). Parte do solo foi acondicionada em vasos plásticos com capacidade para $1 \mathrm{~L}$, nos quais foram colocadas $1.370 \mathrm{~g}$ de solo seco ao ar que, compactado, atingiu densidade de $1,5 \mathrm{~g} \mathrm{~cm}^{-3}$. A outra parte deste foi acondicionada em sacos para mudas, com capacidade para $2 \mathrm{~L}$, nos quais foram acomodadas 1.370 $\mathrm{g}$ de solo, tratamento sem compactação, cuja densidade atingiu $1,0 \mathrm{~g} \mathrm{~cm}^{-3}$.

O delineamento utilizado foi o de blocos casualizados, no esquema fatorial $3 \times 2 \times 2$, com 7 repetições. Os tratamentos, conduzidos em cultivo protegido, consistiram de 3 doses de resíduo agroindustrial $\left(0 ; 15\right.$ e $\left.30 \mathrm{t} \mathrm{ha}^{-1}\right)$, duas densidades $\left(1,0\right.$ e $\left.1,5 \mathrm{~g} \mathrm{~cm}^{-3}\right)$ e duas plantas indicadoras (Astronium fraxinifolium e Dipteryx alata). As plantas selecionadas são espécies arbóreas de

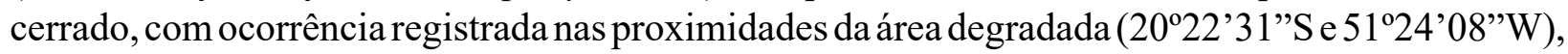
onde o solo foi coletado. As plantas foram irrigadas diariamente com água purificada em sistema de osmose reversa.

O solo coletado tem textura argilosa (areia: $482 \mathrm{~g} \mathrm{~kg}^{-1}$ solo; silte: $101 \mathrm{~g} \mathrm{~kg}^{-1}$ solo e argila: $417 \mathrm{~g} \mathrm{~kg}^{-1}$ solo; EMBRAPA, 1997) e apresenta baixa disponibilidade de nutrientes ( $\mathrm{P}=3,0 \mathrm{mg}$ $\mathrm{dm}^{-3} ; \mathrm{pH} \mathrm{CaCl}_{2}=4,5 ; \mathrm{MO}=10,0 \mathrm{~g} \mathrm{dm}^{-3} ; \mathrm{K}=0,6 \mathrm{mmol}_{\mathrm{c}} \mathrm{dm}^{-3} ; \mathrm{Ca}=1,0 \mathrm{mmol}_{\mathrm{c}} \mathrm{dm}^{-3} ; \mathrm{Mg}=1,0$ $\mathrm{mmol}_{\mathrm{c}} \mathrm{dm}^{-3} ; \mathrm{Al}=5,0 \mathrm{mmol}_{\mathrm{c}} \mathrm{dm}^{-3} ; \mathrm{H}+\mathrm{Al}=26,0 \mathrm{mmol}_{\mathrm{c}} \mathrm{dm}^{-3} ; \mathrm{CTC}=29,0 \mathrm{mmol}_{\mathrm{c}} \mathrm{dm}^{-3} ; \mathrm{SB}=2,4$ $\mathrm{mmol}_{\mathrm{c}} \mathrm{dm}^{-3} ; \mathrm{V}=8,3 \%$ e saturação por alumínio $(\mathrm{m})=17,2 \%$ ), em análise realizada de acordo com Raij et al. (2001).

O resíduo agroindustrial utilizado é uma cinza produzida pela queima do bagaço da canade-açúcar, em caldeiras, nas usinas de produção de açúcar e álcool presentes na região. Este resíduo agroindustrial, oriundo da Usina Alcoolvale: açúcar e álcool S.A., em Aparecida do Taboado MS, apresenta a seguinte composição química, determinada de acordo como Raij et al. (2001): $\left.\mathrm{P}=167,0 \mathrm{mg} \mathrm{dm}{ }^{-3} ; \mathrm{pH} \mathrm{CaCl}_{2}=8,9 ; \mathrm{MO}=28,0 \mathrm{~g} \mathrm{dm}^{-3} ; \mathrm{K}\right)=36,6 \mathrm{mmol}_{\mathrm{c}} \mathrm{dm}^{-3} ; \mathrm{Ca}=242,0 \mathrm{mmol}_{\mathrm{c}}$ $\mathrm{dm}^{-3} ; \mathrm{Mg}=23,0 \mathrm{mmol}_{\mathrm{c}} \mathrm{dm}^{-3}$ e $\mathrm{Al}=0,0 \mathrm{mmol}_{\mathrm{c}} \mathrm{dm}^{-3}$. Ressalta-se que esta análise indica apenas os teores disponíveis e não os totais presentes no material.

Para simular as densidades desejadas $\left(1,0\right.$ e $\left.1,5 \mathrm{~g} \mathrm{~cm}^{-3}\right)$ assumiu-se que o solo colocado no vaso, sem nenhum ajuste, estaria com sua densidade em torno de $1,0 \mathrm{~g} \mathrm{~cm}^{-3}$, utilizou-se o vaso para registrar o peso de solo necessário para encher o vaso. Após várias repetições (10 pesagens), o valor médio obtido foi de $913 \mathrm{~g}$.

Para montar as unidades experimentais com densidade $1,5 \mathrm{~g} \mathrm{~cm}^{-3}$, partiu-se do pressuposto que, para aumentar a densidade em $50 \%$, seriam necessários $50 \%$ a mais de solo, o que resulta em $1.370 \mathrm{~g}$ de solo por vaso com capacidade para $1 \mathrm{~L}$. Esta quantidade de solo, incorporada das doses de resíduo agroindustrial, foi então compactada dentro dos vasos até a marca de $1 \mathrm{~L}$.

Todas as unidades experimentais com densidade $1,0 \mathrm{~g} \mathrm{~cm}^{-3}$ foram preparadas com a mesma quantidade de solo (1.370 g), adicionados da dose indicada de resíduo agroindustrial, que foi incorporado ao material para depois ser acondicionado na unidade experimental, neste caso sacos para mudas com capacidade para $2 \mathrm{~L}$.

Para garantir que a densidade havia sido atingida foram preparados 6 vasos adicionais, os quais foram umedecidos e, de três deles uma amostra central foi coletada com anel volumétrico (EMBRAPA, 1997), que apresentou resultado satisfatório, produzindo a densidade esperada nos vasos. Os outros três (3) vasos adicionais preparados permaneceram ao lado do experimento e foram tratados como parte deste, no que diz respeito à irrigação, para ao final do experimento medir suas densidades.

Nas unidades experimentais com densidade $1,0 \mathrm{~g} \mathrm{~cm}^{-3}$ não foi possível aferir a densidade no início do experimento, devido à fragilidade do sistema, mas ao final do experimento a densidade foi medida em 3 unidades, como na situação anterior.

As sementes de Dipteryx alata passaram por tratamento pré-germinativo, ou seja, o 
pericarpo (epicarpo, mesocarpo e endocarpo) foi removido mecanicamente com a ajuda de martelo e alicate. As sementes das duas espécies passaram por desinfecção com imersão em $\mathrm{HCl} 0,1 \%$, por um minuto, seguida de lavagem em água purificada. As sementes foram introduzidas, duas a duas, nas unidades experimentais, até seu recobrimento com o substrato, em 10 de setembro de 2011. Após 70 dias da semeadura (20 de novembro/2011) foi realizado o desbaste, com auxílio de tesoura, deixando uma planta por unidade experimental.

Ao final do experimento, em 20 de junho de 2012, sete meses após o desbaste, as mudas foram avaliadas quanto à altura, diâmetro do caule, número de folhas, massa fresca e seca da parte aérea e do sistema radicular. As raízes coletadas foram lavadas em água corrente, secas com papeltoalha, pesadas e fotografadas, para observação de sua morfologia, antes de serem colocadas em sacos de papel pardo e secas em estufa $\left(60^{\circ} \mathrm{C}\right)$ com circulação forçada de ar por $72 \mathrm{~h}$. O solo foi então coletado e analisado para fertilidade segundo Raij et al. (2001).

Os dados coletados foram avaliados estatisticamente em análise de variância, seguida de testes de médias (Tukey) e regressão para doses, utilizando-se o programa estatístico SISVAR (FERREIRA, 2000).

\section{RESULTADOS E DISCUSSÃO}

No início do experimento, para obtenção da densidade de $1,5 \mathrm{~g} \mathrm{~cm}^{-3}$ foi necessário compactar o solo, mas com o passar do tempo isto acabou acontecendo naturalmente, até mesmo nas unidades experimentais compactadas ocorreu incremento na densidade $\left(1,71 ; 1,55 \mathrm{e} 1,72 \mathrm{~g} \mathrm{~cm}^{-3}\right)$. Este fato coloca, ao final do período experimental, todas as plantas expostas a um substrato compactado ou adensado, reduzindo as evidencias de sensibilidade, ou não, das mudas à densidade elevada, mas leva a outra observação importante sobre o substrato, ou seja, sobre a capacidade que as partículas deste apresentaram em se organizar ou reorganizar.

Problemas com adensamento do solo vêm sendo reportados ao longo do tempo, em diferentes situações e regiões (GOMES, 1996; MALTONI, 1994; OLIVEIRA, 1994; MONIZ, 1996; SILVA, 2000). O adensamento, diferentemente da compactação, não depende de esforço mecânico para seu desenvolvimento, o que é compatível com o que foi observado no experimento. Pesquisadores têm associado este processo ao tipo de textura do solo, ao arranjo entre as partículas, ao formato das partículas e aos ciclos de umedecimento e secagem a que os solos estão expostos (STITT et al., 1982; OLIVEIRA et al., 1992; OLIVEIRA, 1994).

Um solo argiloso, segundo Oliveira, Jacomine e Camargo (1992), apresenta maior propensão ao adensamento do que um solo arenoso, devido à sua plasticidade e coesão, bem como à migração das frações finas pela eluviação, promovendo o rearranjo das partículas, causando obstrução de macroporos e redução da taxa de infiltração de água no solo.

O predomínio de areia fina no solo promove um melhor ajuste de partículas, com as partículas menores se alojando nos espaços vazios existentes entre as partículas maiores, reduzindo o espaço poroso e aumentando a densidade, o que é favorecido quando partículas esféricas e de tamanhos distintos são predominantes, pois favorecem um melhor ajuste das partículas, se comparado com partículas angulosas (STITT et al., 1982; MALTONI, 1994). A esta discussão é necessário, ainda, incluir os ciclos de umedecimento e secagem, como fator decisivo no processo de adensamento dos solos (OLIVEIRA, 1994).

Importante acrescentar que este processo ocorreu ao longo dos 10 meses do experimento, de forma que, apenas metade das mudas se encontrava em solo compactado no início de seu crescimento, o que permitiu prosseguir com as observações. Estas mostraram que a fertilidade do solo e o crescimento das plantas foram influenciados pela compactação (Tabelas 1, 2 e 3). 
A partir dos resultados da análise de fertilidade (Tabela 1) verificou-se que as plantas utilizadas não promoveram nenhuma modificação distintiva na fertilidade do substrato. As densidades avaliadas $\left(1,0\right.$ e 1,5 $\left.\mathrm{g} \mathrm{cm}^{-3}\right)$ mostraram efeito significativo para teores de $\mathrm{Ca}, \mathrm{Mg}, \mathrm{Al}$, $\mathrm{SB}, \mathrm{V}$ e $\mathrm{m}$ (saturação por alumínio). Os três últimos não serão discutidos, pois são consequências da presença de bases e alumínio no substrato.

Sabendo que Ca e Mg são móveis no solo, a redução na infiltração de água, promovida pela compactação inicial do substrato, pode ter diminuído as perdas destes por lixiviação, ocasionando a presença de maiores teores de $\mathrm{Ca}$ e $\mathrm{Mg}$ no substrato inicialmente compactado (Tabela 1).

Avaliando um solo francoarenoso, com densidades de 1,79 e 1,85 $\mathrm{g} \mathrm{cm}^{-3}$ após sucessivas irrigações, Mandal, Kar e Sharma (1990) atribuíram a maior concentração de nitrato e a menor perda por lixiviação (3 a 4 vezes menor), à maior densidade ou maior grau de compactação, contribuindo para explicar o processo de manutenção dos níveis mais elevados de $\mathrm{Ca}$ e $\mathrm{Mg}$ observados neste experimento.

O oposto ocorre com o Al (Tabela 1), que apresenta os menores teores no substrato compactado e resposta linear e negativa (Tabela 2) às doses de resíduo agroindustrial aplicadas, isto é, seus valores são reduzidos à medida que as doses aumentam.

Tal comportamento pode ser explicado pela ausência de Al trocável no resíduo agroindustrial e pelo contato do Al do substrato, com partículas do resíduo, o qual apresenta $\mathrm{pH}=8,9$ e pode, pontualmente, ter contribuído para tornar indisponível parte do Al presente no substrato compactado. De acordo com Catani e Alonso (1969), a elevação do $\mathrm{pH}$ a valores superiores a 5,4 faz com que as formas trocáveis e polímeros parcialmente hidrolisados de Al transformem-se em $\mathrm{Al}(\mathrm{OH})_{3}$, que, por estar na forma neutra e insolúvel, tem sua atividade reduzida, explicando o comportamento do Al.

As doses de resíduo agroindustrial incorporados ao solo influenciaram também $\mathrm{MO}, \mathrm{pH}$, $\mathrm{K}, \mathrm{Ca}, \mathrm{Mg}$, e CTC, sendo está última variável resultado da soma de bases e alumínio trocáveis, portanto a mesma não será discutida (Tabelas 1 e 2).

Embora o conteúdo de $\mathrm{P}$ indicado como disponível no resíduo agroindustrial seja da ordem de $167,0 \mathrm{mg} \mathrm{dm}^{-3}$ e o P do solo utilizado seja de $3,0 \mathrm{mg} \mathrm{dm}^{-3}$, os resultados mostram ausência de influência da cinza sobre o solo (Tabela 1). Sabe-se que o P do solo é um elemento de baixa mobilidade e que pode ser adsorvido por óxidos de ferro e hidróxidos de alumínio encontrados na fração argila, processo importante na presença de $\mathrm{pH}$ ácido e solos bastante intemperizados, em que o $\mathrm{P}$ pode ser adsorvido, deixando de estar disponível às plantas (BRENNAM et al., 1994; FONTES; WEED, 1996; KER et al., 1996; BEDIN et al., 2003). Isto explica parcialmente a ausência de efeitos da aplicação do resíduo ao solo, que é argiloso (417 $\mathrm{g} \mathrm{kg}^{-1}$ argila), ácido (pH varia de 4,00 a 4,75) e, por ser vermelho, indica presença de óxidos de ferro do tipo hematita (RESENDE, 1976; SCHWERTMANN, 1993).

O conteúdo de MO no substrato foi influenciado, linear e positivamente, pelas doses aplicadas do resíduo agroindustrial $\left(\mathrm{Y}=6,6389^{* *}+0,2500 \mathrm{x}^{* *} / \mathrm{R}^{2}=0,9643\right)$, bem como pela interação destas doses com a densidade (Tabela 2), cujo maior conteúdo de $\mathrm{MO}\left(7,83 \mathrm{~g} \mathrm{dm}^{-3}\right)$ ocorre na maior dose de resíduo agroindustrial e na maior densidade. Na maior dose do resíduo, os incrementos em MO são atribuídos ao aporte produzido pela adição do mesmo que, embora calcinado, apresenta $28,0 \mathrm{~g} \mathrm{dm}^{-3}$ de MO. Na realidade, este apresenta carbono em sua constituição devido à combustão incompleta do bagaço, como também relatado por Payá et al. (2002) e Cordeiro, Toledo Filho e Fairbairn (2009). Considerar que este resultado foi significativo na maior densidade leva a inferir que a MO foi preservada nas unidades experimentais de maior densidade, pois diminui a presença de $\mathrm{O}_{2}$ e dificulta a ação dos microrganismos decompositores, protegendo a MO (MAYER et al., 2004; MCCARTHY et al., 2008). 
TABELA 1: Médias de $\mathrm{P}, \mathrm{MO}, \mathrm{pH}, \mathrm{K}, \mathrm{Ca}, \mathrm{Mg}$, acidez potencial (H+Al), Al, soma de bases (SB), capacidade de troca catiônica (CTC), saturação por bases (V), saturação por alumínio (Al), probabilidade de F e coeficiente de variação $(\mathrm{CV})$, para o substrato, em função dos tratamentos.

TABLE 1: Average of $\mathrm{P}, \mathrm{MO}, \mathrm{pH}, \mathrm{K}, \mathrm{Ca}, \mathrm{Mg}$, potential acidity ( $\mathrm{H}+\mathrm{Al}), \mathrm{Al}$, sum of bases (SB), cation exchange capacity (CTC), bases saturation (V), aluminum saturation (m), F probability and coefficient of variation $(\mathrm{CV})$, for substratum, according to the treatments.

\begin{tabular}{|c|c|c|c|c|c|c|c|c|c|c|c|c|}
\hline \multirow{2}{*}{ Fontes de Variação } & $\mathrm{P}$ & $\mathrm{MO}$ & $\mathrm{pH}$ & $\mathrm{K}$ & $\mathrm{Ca}$ & $\mathrm{Mg}$ & $\mathrm{H}+\mathrm{Al}$ & $\mathrm{Al}$ & SB & $\mathrm{CTC}$ & $\mathrm{V}$ & $\mathrm{m}$ \\
\hline & $\mathrm{mgdm}^{-3}$ & $\mathrm{~g} \mathrm{dm}^{-3}$ & $\mathrm{CaCl}_{2}$ & \multicolumn{3}{|c|}{ 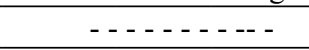 } & \multicolumn{3}{|c|}{$\mathrm{mmol}_{c} \mathrm{dm}^{-3}$} & -- & \multicolumn{2}{|c|}{$------\% 0^{-----}$} \\
\hline \multicolumn{13}{|c|}{ Plantas (PL) } \\
\hline Baru & 2,0 & 7,1 & 4,4 & 0,7 & 1,7 & 1,2 & 22,9 & 6,2 & 3,6 & 26,4 & 12,7 & 64,3 \\
\hline Gonçalo-alves & 2,1 & 7,2 & 4,4 & 0,7 & 1,7 & 1,2 & 22,9 & 6,4 & 3,6 & 26,5 & 12,8 & 64,9 \\
\hline \multicolumn{13}{|c|}{ Densidade do Substrato em $\mathrm{g} \mathrm{cm}^{-3}$ (DS) } \\
\hline $1,0 \mathrm{~g} \mathrm{~cm}^{-3}$ & 2,1 & 7,1 & 4,4 & 0,7 & $1,4 \mathrm{~b}$ & $1,1 \mathrm{~b}$ & 22,9 & $7,2 \mathrm{a}$ & $3,2 \mathrm{~b}$ & 26,1 & $11,6 b$ & $70,3 \mathrm{a}$ \\
\hline $1,5 \mathrm{~g} \mathrm{~cm}^{-3}$ & 2,0 & 7,2 & 4,4 & 0,7 & $1,9 \mathrm{a}$ & $1,3 \mathrm{a}$ & 22,9 & $5,3 \mathrm{~b}$ & $3,9 \mathrm{a}$ & 26,8 & $13,9 \mathrm{a}$ & $58,9 \mathrm{~b}$ \\
\hline \multicolumn{13}{|c|}{ Doses de Resíduo Agroindustrial em $\mathrm{Mg} \mathrm{ha}^{-1}$ (RA) } \\
\hline 00 & 2,0 & 6,9 & 4,0 & 0,8 & 1,0 & 1,0 & 22,4 & 7,1 & 2,1 & 24,5 & 9,4 & 74,7 \\
\hline 15 & 2,1 & 7,1 & 4,4 & 1,0 & 1,7 & 1,0 & 22,9 & 6,7 & 3,7 & 26,6 & 12,4 & 66,8 \\
\hline 30 & 2,0 & 7,4 & 4,8 & 1,0 & 2,4 & 1,5 & 23,4 & 5,1 & 4,9 & 28,3 & 16,3 & 52,4 \\
\hline \multicolumn{13}{|c|}{ Probabilidade de $\mathrm{F}$} \\
\hline PL & $1,0^{\mathrm{ns}}$ & $3,22^{\text {ns }}$ & $0,00^{\text {ns }}$ & $1,00^{\text {ns }}$ & $0,16^{\mathrm{ns}}$ & $0,00^{\mathrm{ns}}$ & $0,02^{\mathrm{ns}}$ & $3,63^{\text {ns }}$ & $0,00^{\mathrm{ns}}$ & $0,02^{\text {ns }}$ & $0,03^{\text {ns }}$ & $0,33^{\text {ns }}$ \\
\hline DS & $1,0^{\mathrm{ns}}$ & $3,22^{\mathrm{ns}}$ & $0,00^{\mathrm{ns}}$ & $1,00^{\mathrm{ns}}$ & $12,70^{* *}$ & $7,73^{* *}$ & $0,02^{\mathrm{ns}}$ & $261,91^{* *}$ & $19,74^{* *}$ & $3,23^{\mathrm{ns}}$ & $15,08^{* *}$ & $113,30^{* *}$ \\
\hline $\mathrm{CZ}$ & $1,0^{\mathrm{ns}}$ & $10,03^{* *}$ & $9,83^{* *}$ & $121,00^{* *}$ & $34,02^{* *}$ & $17,40^{* *}$ & $2,30^{\mathrm{ns}}$ & $108,98^{* *}$ & $87,71^{* *}$ & $30,42^{* *}$ & $44,43^{* *}$ & $148,35^{* *}$ \\
\hline $\mathrm{DS} * \mathrm{CZ}$ & $1,0^{\mathrm{ns}}$ & $12,89^{* *}$ & $0,48^{\mathrm{ns}}$ & $1,00^{\mathrm{ns}}$ & $6,11^{* *}$ & $7,73^{* *}$ & $2,64^{\mathrm{ns}}$ & $1,59^{\mathrm{ns}}$ & $9,14^{* *}$ & $8,16^{* *}$ & $3,87^{*}$ & $13,28^{* *}$ \\
\hline $\mathrm{CV}(\%)$ & 8 & 4 & 9 & 24 & 25 & 21 & 5 & 6 & 15 & 5 & 14 & 5 \\
\hline
\end{tabular}

Em que: Médias seguidas de mesma letra, nas colunas, por fonte de variação, não diferem significativamente entre si pelo teste Tukey a $5 \%$. ns $=$ valores não significativos; ${ }^{* *} \mathrm{e}^{*}=$ valores significativos para $\mathrm{P} \leq 0,01 \mathrm{e} \leq 0,05$, respectivamente.

$\mathrm{O} \mathrm{pH}$ do solo respondeu positiva e linearmente às doses crescentes de resíduo aplicadas (Tabelas 1 e 2). $\mathrm{O}$ resíduo agroindustrial apresenta $\mathrm{pH}=8,9$, adiciona bases e, assim, explica o incremento de pH ocorrido no substrato. Feitosa, Maltoni e Silva (2009) também observaram incrementos no $\mathrm{pH}$ do solo devido à incorporação de resíduo (cinza) oriundo da queima do bagaço da cana-de-açúcar, apontando positivamente à utilização da mesma. Pita (2009) utilizando o mesmo tipo de resíduo, verificou que, comparativamente aos calcários calcítico e dolomítico, este originou maior e mais rápido incremento no $\mathrm{pH}$ do solo, indicando vantagem em sua utilização. Brunelli e Pisani Junior (2004) verificaram que uma tonelada de cinza equivale a 0,5 toneladas de calcário, permitindo sugerir que o uso deste resíduo agroindustrial como substituto, ao menos parcial da calagem, gera economia ao processo produtivo.

Comportamento semelhante foi verificado para o $\mathrm{K}$, com resposta linear e crescente em função da dose de resíduo agroindustrial aplicada (Tabelas 1 e 2). A quantidade de $\mathrm{K}$ presente no resíduo $\left(36,6 \mathrm{mmol}_{\mathrm{c}} \mathrm{dm}^{-3}\right)$ e no solo $\left(0,6 \mathrm{mmol}_{\mathrm{c}} \mathrm{dm}^{-3}\right)$ indicam que ocorreram incrementos importantes nos conteúdos de K no substrato. Resultados favoráveis também foram reportados por Pita (2009) e Feitosa, Maltoni e Silva (2009), sugerindo o uso deste resíduo como fonte de K para o solo.

Tanto Ca quanto $\mathrm{Mg}$ responderam à aplicação do resíduo agroindustrial (Tabela 1), sendo observada interação entre as doses do resíduo e a densidade, o que leva a uma análise mais detalhada (Tabela 2). O Ca apresenta resposta linear à aplicação das doses do resíduo, nas duas densidades, 
TABELA 2: Equações de regressão, significância de seus termos e valores de $\mathrm{R}^{2}$, para as variáveis do substrato avaliadas, em relação às doses de resíduo agroindustrial (RA) e seus desdobramentos, devido à resposta positiva da interação doses de RA x densidade.

TABLE 2: Regression equations, significance of their terms and $\mathrm{R}^{2}$ values, for the substratum variables assessed, in relation to the doses of agro-industrial residues (RA), and its positive response due to the interaction of RA doses $\mathrm{x}$ density.

\section{Variáveis Analisadas}

Equações de Regressão para Doses de RA $\quad \mathrm{R}^{2} \quad$ Interação Doses de RA x Densidade do Substrato $\quad \mathrm{R}^{2}$

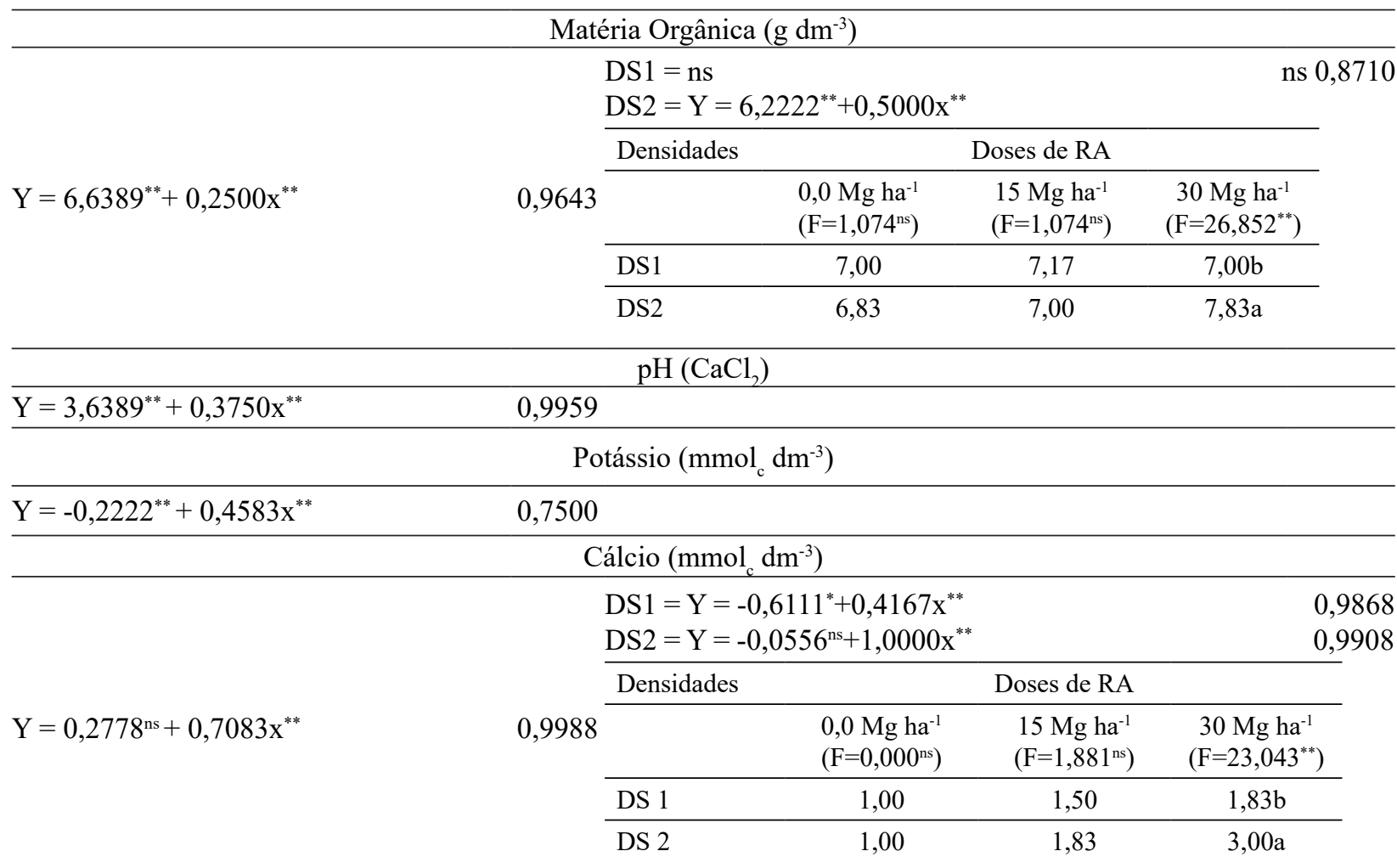

\begin{tabular}{|c|c|c|c|c|c|}
\hline \multicolumn{6}{|c|}{ Magnésio $\left(\mathrm{mmol}_{\mathrm{c}} \mathrm{dm}^{-3}\right)$} \\
\hline \multirow{5}{*}{$Y=1,5000^{* *}-0,750 x^{*}+0,2500 x^{2 * *}$} & \multirow{5}{*}{0,9998} & $\begin{array}{l}\mathrm{DS} 1=\mathrm{ns} \\
\mathrm{DS} 2=\mathrm{Y}=1\end{array}$ & $3^{* *}-1,2500 x^{*}+$ & $4167 x^{2^{* *}}$ & \multirow[t]{2}{*}{ ns 0,9998} \\
\hline & & Densidades & & Doses de RA & \\
\hline & & & $\begin{array}{l}0,0 \mathrm{Mg} \mathrm{ha}^{-1} \\
\left(\mathrm{~F}=0,000^{\mathrm{ns}}\right)\end{array}$ & $\begin{array}{l}15 \mathrm{Mg} \mathrm{ha}^{-1} \\
\left(\mathrm{~F}=0,000^{\mathrm{ns}}\right)\end{array}$ & $\begin{array}{c}30 \mathrm{Mg} \mathrm{ha}^{-1} \\
\left(\mathrm{~F}=23,200^{* *}\right)\end{array}$ \\
\hline & & DS 1 & 1,00 & 1,00 & $1,17 \mathrm{~b}$ \\
\hline & & DS 2 & 1,00 & 1,00 & $1,83 \mathrm{a}$ \\
\hline \multicolumn{6}{|c|}{ Alumínio $\left(\mathrm{mmol}_{\mathrm{c}} \mathrm{dm}^{-3}\right)$} \\
\hline $\mathrm{Y}=8,2778^{* *}-1,0000 \mathrm{x}^{* *}$ & 0,8981 & & & & \\
\hline
\end{tabular}

com efeitos importantes quando o resíduo foi aplicado na dose de $30 \mathrm{Mg} \mathrm{ha}^{-1} \mathrm{e}$ na maior densidade $\left(1,5 \mathrm{~g} \mathrm{~cm}^{-3}\right)$. Comportamento explicado pela redução da taxa de infiltração de água no solo em ambientes mais compactados/adensados, como discutido anteriormente. Vale ressaltar que os incrementos em $\mathrm{Ca}$ foram mais elevados que $100 \%$ se forem consideradas a ausência de resíduo agroindustrial e a dose mais elevada do mesmo (Tabela 1). 
$\mathrm{O} \mathrm{Mg}$ mostrou resposta quadrática às doses de resíduo agroindustrial quando o substrato apresentou maior densidade, com maiores valores na dose de $30 \mathrm{Mg} \mathrm{ha}^{-1}$ de resíduo, nas quais se observou um incremento em $\mathrm{Mg}$ da ordem de $50 \%$, indicando que a utilização deste resíduo contribui para fornecimento de $\mathrm{Mg}$ ao solo.

Os poucos trabalhos conduzidos para avaliar a utilização deste tipo de resíduo como substituto parcial de insumos e na melhoria da condição de fertilidade dos solos, indicam como promissor o uso da cinza produzida a partir da queima do bagaço da cana-de-açúcar, em caldeiras de usinas de açúcar e álcool (FEITOSA et al., 2009; PITA, 2009; THIND et al., 2012). Esta preocupação com o uso de resíduos passou, recentemente, a fazer parte dos planos de desenvolvimento de todas as atividades econômicas e, particularmente, das maiores produtoras de resíduos, que devem responder legalmente por sua adequada disposição.

$\mathrm{Na}$ análise das plantas indicadoras observou-se que a densidade inicial $\left(1,0\right.$ e 1,5 $\left.\mathrm{g} \mathrm{cm}^{-3}\right)$ influenciou negativamente a massa fresca da raiz de ambas e a altura do Astronium fraxinifolium (Tabela 3).

Trabalhando com eucalipto, Reis et al. (1989) afirmam que a forma, a profundidade e a distribuição das raízes dependem do ambiente e do potencial genético de cada espécie, mas impedimentos físicos ou químicos do solo podem dificultar o pleno desenvolvimento das raízes. Outros autores têm relatado que as raízes apresentam dificuldade em penetrar verticalmente as camadas de solo compactadas (BEJARANO et al., 2010), contribuindo para explicar a morfologia observada no presente trabalho.

Shepherd (1986) relata que as malformações causadas nas raízes de arbóreas pelos recipientes na fase de produção de mudas podem provocar problemas nas plantas adultas depois de vários anos. $\mathrm{O}$ autor alerta para a necessidade de bom condicionamento do solo no momento do plantio das mudas, para que não ocorram malformações no sistema radicular, cujas consequências serão notadas tardiamente. Neves et al. (2005) avaliando a arquitetura das raízes de acácianegra observaram que a densidade está entre as condições físicas do solo que dificultam o pleno desenvolvimento radicular da espécie.

As raízes de Dipteryx alata e de Astronium fraxinifolium apresentaram dificuldades para crescer no solo mais compactado apresentando, como consequência, menor massa fresca do sistema radicular, o que no caso do Astronium fraxinifolium influenciou também sua altura. O resultado sugere ser esta planta mais sensível à compactação do que o Dipteryx alata, que não apresentou resposta significativa à maioria dos tratamentos impostos.

Previtali (2007), trabalhando com mudas de pupunha em vaso com diferentes níveis de compactação e diferentes solos, verificou que a pupunha tem seu crescimento em altura comprometido em solos argilosos compactados. Medeiros, Soares e Guimarães (2005), avaliando o efeito da compactação sobre plantas de arroz, observaram comprometimento na produção de massa seca na presença da compactação, o que corrobora a observação feita para o Astronium fraxinifolium, também em solo argiloso.

As doses de resíduo agroindustrial influenciaram positivamente o crescimento do Astronium fraxinifolium em todas as medidas feitas (Tabela 3). A interação entre densidade e as doses de resíduo influenciaram a massa fresca e seca da parte aérea (Tabela 4), permitindo inferir que o Astronium fraxinilolium mostrou ser mais exigente do que o Dipteryx alata no que diz respeito à fertilidade do solo, e que a densidade influenciou o crescimento das plantas, por interferir no desenvolvimento do sistema radicular.

Incrementos na densidade, de acordo com Lipiec e Stcpniewski (1995) e Tavares Filho e Barbosa (2001), podem interferir no crescimento da raiz e em sua morfologia, independentemente do regime de umidade. Este fato foi observado no presente trabalho, pois ao coletar as plantas e 
TABELA 3: Valores médios de altura (H), diâmetro do caule (DC), número de folhas (NF), massa fresca (MFPA) e seca (MSPA) da parte aérea, massa fresca (MFR) e seca (MSR) do sistema radicular, probabilidade de $\mathrm{F}$ e coeficiente de variação $(\mathrm{CV})$, para mudas de Dipteryx alata e Astronium fraxinifolium, sob diferentes densidades (DS) e doses de resíduo agroindustrial (RA).

TABLE 3: Averages of height (H), stem diameter (DC), number of leaves (NF); fresh mass (MFPA) and dry (MSPA) of aerial part, fresh mass (MFR) and dry (MSR) of root system, $\mathrm{F}$ probability and coefficient of variation $(\mathrm{CV})$, for seedlings of Dipteryx alata, and Astronium fraxinifolium under different densities (DS) and doses of agro-industrial residue (RA).

\begin{tabular}{|c|c|c|c|c|c|c|c|}
\hline \multirow{2}{*}{ Fontes de Variação } & \multirow{2}{*}{$\underset{\mathrm{cm}}{\mathrm{H}}$} & \multirow{2}{*}{$\begin{array}{c}\mathrm{DC} \\
\mathrm{mm}\end{array}$} & \multirow{2}{*}{$\mathrm{NF}$} & \multirow{2}{*}{ MFPA } & MSPA & MFR & MSR \\
\hline & & & & & \multicolumn{3}{|c|}{$\ldots \ldots-\ldots$} \\
\hline \multicolumn{8}{|c|}{ Dipteryx alata } \\
\hline \multicolumn{8}{|c|}{ Densidade do Substrato (DS) } \\
\hline $1,0 \mathrm{~g} \mathrm{~cm}^{-3}$ & 14,7 & 5,09 & 4,05 & 3,09 & 1,81 & $5,81 \mathrm{a}$ & 2,62 \\
\hline $1,5 \mathrm{~g} \mathrm{~cm}^{-3}$ & 13,7 & 5,29 & 4,05 & 2,71 & 1,52 & $3,76 b$ & 2,14 \\
\hline \multicolumn{8}{|c|}{ Doses do Resíduo Agroindustrial (RA) } \\
\hline $0 \mathrm{t} \mathrm{ha}^{-1}$ & 14,4 & 5,00 & 4,36 & 2,71 & 1,50 & 4,29 & 2,21 \\
\hline $15 \mathrm{t} \mathrm{ha}^{-1}$ & 13,7 & 5,21 & 3,57 & 2,93 & 1,79 & 4,93 & 2,36 \\
\hline $30 \mathrm{t} \mathrm{ha}^{-1}$ & 14,4 & 5,36 & 4,21 & 3,07 & 1,71 & 5,14 & 2,57 \\
\hline \multicolumn{8}{|l|}{ Probabilidade de F } \\
\hline DS & $2,367^{\mathrm{ns}}$ & $0,814^{\mathrm{ns}}$ & $0,000^{\mathrm{ns}}$ & $1,215^{\mathrm{ns}}$ & $1,742^{\mathrm{ns}}$ & $12,437^{* *}$ & $2,362^{\text {ns }}$ \\
\hline RA & $0,592^{\mathrm{ns}}$ & $0,966^{\mathrm{ns}}$ & $1,231^{\text {ns }}$ & $0,361^{\text {ns }}$ & $0,629^{\text {ns }}$ & $0,787^{\mathrm{ns}}$ & $0,449^{\text {ns }}$ \\
\hline $\mathrm{DS} * \mathrm{RA}$ & $2,154^{\mathrm{ns}}$ & $0,365^{\mathrm{ns}}$ & $0,323^{\text {ns }}$ & $0,019^{\text {ns }}$ & $0,145^{\text {ns }}$ & $0,007^{\mathrm{ns}}$ & $0,165^{\mathrm{ns}}$ \\
\hline $\mathrm{CV}(\%)$ & 14 & 13 & 35 & 39 & 42 & 39 & 42 \\
\hline \multicolumn{8}{|c|}{ Astronium fraxinifolium } \\
\hline \multicolumn{8}{|c|}{ Densidade do Substrato (DS) } \\
\hline $1,0 \mathrm{~g} \mathrm{~cm}^{-3}$ & $6,5 \mathrm{a}$ & 1,86 & 4,1 & 0,26 & 0,13 & $0,62 \mathrm{a}$ & 0,28 \\
\hline $1,5 \mathrm{~g} \mathrm{~cm}^{-3}$ & $5,3 b$ & 1,71 & 3,6 & 0,20 & 0,09 & $0,27 b$ & 0,19 \\
\hline \multicolumn{8}{|c|}{ Doses de Resíduo Agroindustrial (RA) } \\
\hline $0 \mathrm{t} \mathrm{ha}^{-1}$ & 5,4 & 1,36 & 1,6 & 0,09 & 0,04 & 0,19 & 0,11 \\
\hline $15 \mathrm{tha}^{-1}$ & 5,8 & 1,93 & 4,1 & 0,25 & 0,12 & 0,52 & 0,28 \\
\hline $30 \mathrm{tha}^{-1}$ & 6,4 & 2,07 & 5,8 & 0,35 & 0,16 & 0,62 & 0,32 \\
\hline \multicolumn{8}{|l|}{ Probabilidade de F } \\
\hline DS & $25,338^{* *}$ & $0,931^{\text {ns }}$ & $01,243^{\text {ns }}$ & $0,127^{\mathrm{ns}}$ & $0,368^{\mathrm{ns}}$ & $0,985^{* *}$ & $0,345^{\text {ns }}$ \\
\hline RA & $06,851^{* *}$ & $8,690^{* *}$ & $26,178^{* *}$ & $1,036^{* *}$ & $1,145^{* *}$ & $0,546^{* *}$ & $0,606^{* *}$ \\
\hline $\mathrm{DS} * \mathrm{RA}$ & $00,284^{\mathrm{ns}}$ & $1,241^{\mathrm{ns}}$ & $00,041^{\mathrm{ns}}$ & $0,382^{*}$ & $0,382^{*}$ & $0,183^{\mathrm{ns}}$ & $0,208^{\mathrm{ns}}$ \\
\hline CV (\%) & 13 & 27 & 40 & 65 & 68 & 81 & 70 \\
\hline
\end{tabular}

Em que: Médias seguidas de mesma letra, nas colunas, por fonte de variação, não diferem significativamente entre si pelo teste Tukey a $5 \%$ de probabilidade. ${ }^{\mathrm{n} s}=$ valores não significativos; ${ }^{* *} \mathrm{e}^{*}=$ valores significativos para $\mathrm{P} \leq 0,01 \mathrm{e}$ $\leq 0,05$, respectivamente. 
TABELA 4: Equações de regressão, significância de seus termos e valores de $\mathrm{R}^{2}$, para as variáveis avaliadas em relação às doses de resíduo agroindustrial (RA) e seus desdobramentos, devido à resposta positiva da interação doses de RA x densidade, para Astronium fraxinifolium

TABLE 4: Regression equations, significance of their terms and $\mathrm{R}^{2}$ values, for the variables assessed in relation to the doses of agro-industrial residues (RA), and its positive response due to the interaction of RA doses x density to Astronium fraxinifolium.

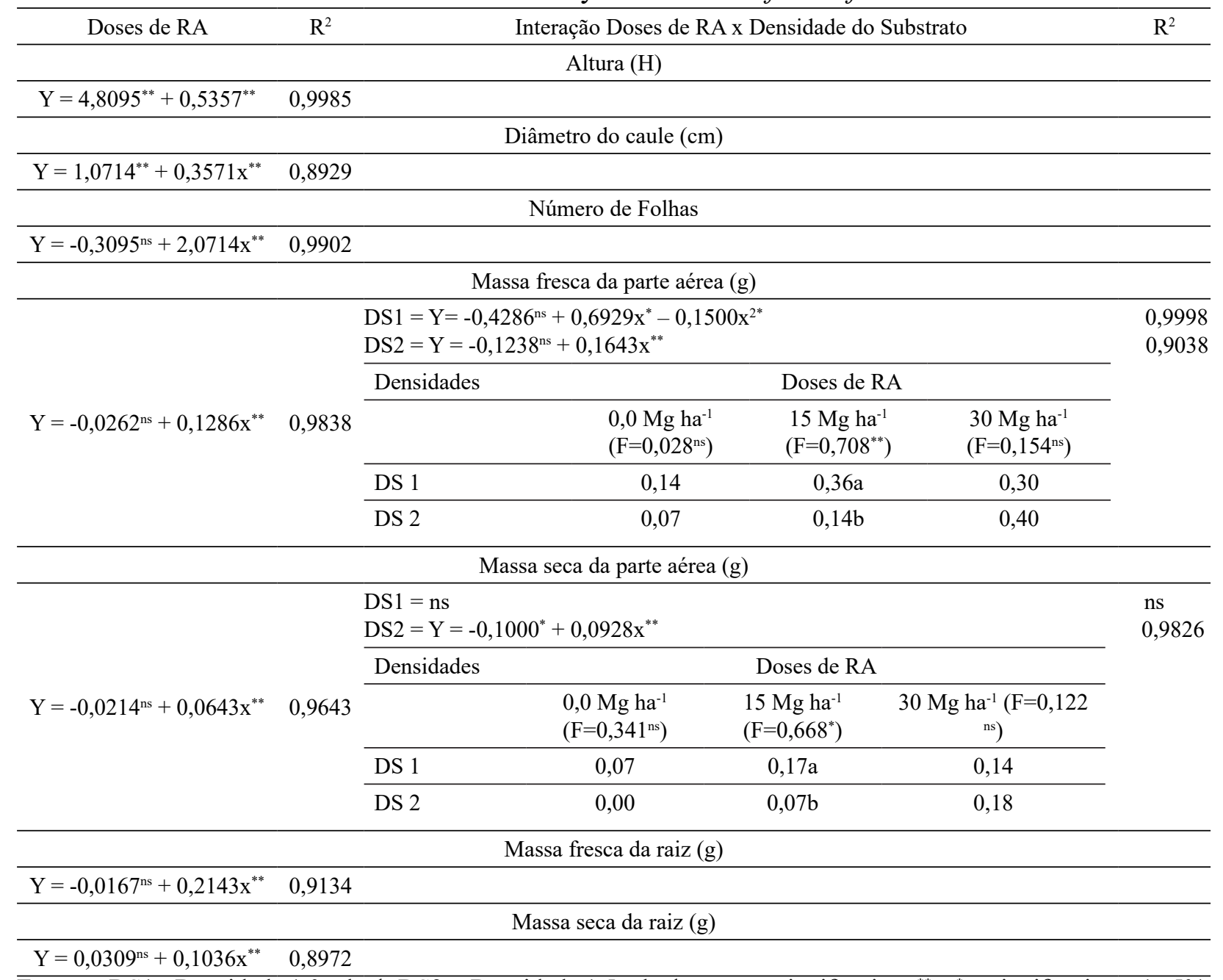

Em que: DS1 = Densidade $1,0 \mathrm{~g} \mathrm{~kg}^{-1} ;$ DS2 $=$ Densidade $1,5 \mathrm{~g} \mathrm{~kg}^{-1} ;{ }^{\mathrm{ns}}=$ não significativo; ${ }^{* *} \mathrm{e}^{*}=$ significativo a 1e $5 \%$, respectivamente. $\mathrm{F}=$ probabilidade de $\mathrm{F}$ 
fotografar o sistema radicular (Figura 1), foi observado comportamento diferenciado das raízes em função da compactação nas unidades experimentais, corroborando com a afirmativa de que o adensamento ocorreu ao longo do tempo, pois as raízes nas unidades experimentais, inicialmente

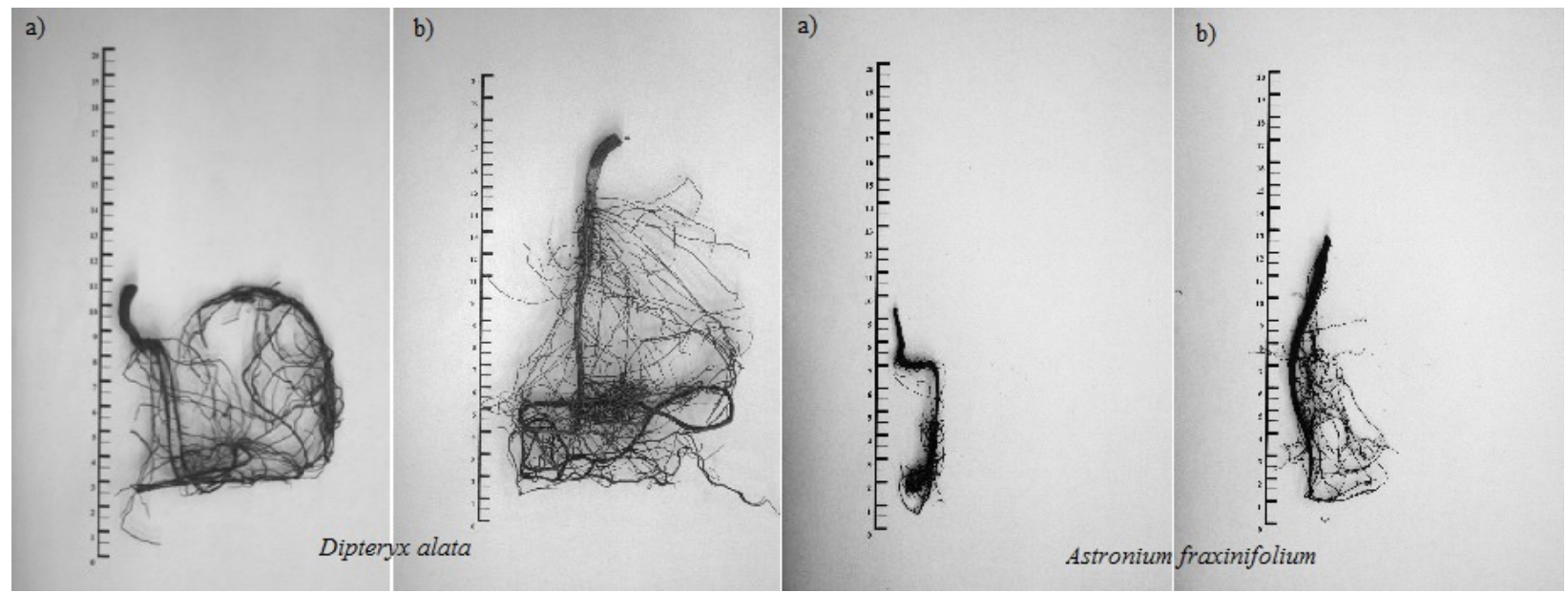

FIGURA 1: Sistema radicular de Dipteryx alata e Astronium fraxinifolium, em unidades experimentais, sendo (a) compactadas e (b) não compactadas (escala em $\mathrm{cm}$ ).

FIGURE 1: Root system of Dipteryx alata and Astronium fraxinifolium, by experimental units, (a) compacted and (b) no compacted (scale in $\mathrm{cm}$ ).

não compactadas estão visualmente mais bem distribuídas. Oliveira et al. (2006) evidenciam a importância de um sistema radicular mais desenvolvido, com maiores quantidades de raízes finas, produzindo mudas mais vigorosas e com mais chances de sobrevivência em ambientes com escassez de nutrientes e água.

\section{CONCLUSÕES}

O resíduo agroindustrial influenciou as condições químicas do solo degradado, elevando o pH e os teores de $\mathrm{K}, \mathrm{Ca}$ e $\mathrm{Mg}$, podendo ser utilizado como condicionante de solo;

O Dipteryx alata teve a massa fresca da raiz influenciada negativamente pela compactação e se mostrou pouco exigente em relação à adição de nutrientes;

O Astronium fraxinifolium teve a massa fresca da raiz e a altura influenciados negativamente pela compactação; e sua altura, diâmetro do caule, massa fresca e seca da parte aérea e da raiz favorecidos pela adição do resíduo agroindustrial;

A morfologia das raízes das duas espécies arbóreas foi alterada pela compactação;

A granulometria do substrato apresentou elevada capacidade de reorganização.

\section{AGRADECIMENTO}

Ao Conselho Nacional de Desenvolvimento Científico e Tecnológico - CNPq pela concessão da bolsa de produtividade ao terceiro autor.

\section{REFERÊNCIAS}

AGUIAR, A. V. et al. Determinação de parâmetros genéticos em população de gonçalo-alves 
(Astronium fraxinifolium) através das características fisiológicas da semente. Scientia Forestalis, Piracicaba, v. 60, p. 89-97, 2001.

AN, S. S.; DARBOUX, F.; CHENG, M. Revegetation as an efficient means of increasing soil aggregate stability on the Loess Plateau (China). Geoderma, Amsterdam, v. 209/210, p. 75-85, 2013.

BEDIN, I.; FURTINI NETO, A. E.; RESENDE, A. V. Fertilizantes fosfatados e produção de soja em solos com diferentes capacidades tampão de fosfato. Revista Brasileira de Ciência do Solo, Viçosa, MG, v. 27, n. 4, p. 639-646, 2003.

BEJARANO, M. D. et al. Effects of soil compaction and light on growth of Quercus pyrenaica Willd. (Fagaceae) seedlings. Soil \& Tillage Research, Amsterdam, v. 110, p. 108-114, 2010.

BRENNAN, R. F. et al. Phosphorus adsorption by a range of western Australian soils related to soil properties. Communications Soil Science Plant Analysis, New York, v. 25, n. 15/16, p. 2785-2795, 1994.

BRUNELLI, A. M. M. P.; PISANI JÚNIOR, R. Proposta de disposição de resíduo gerado a partir da queima do bagaço de cana em caldeiras como fonte de nutriente e corretivo do solo. In: CONGRESO INTERAMERICANO DE INGENIERÍA SANITARIA Y AMBIENTAL, 30., 2006, Punta del Leste. Anais... Punta del Leste: Asociación Interamericana de Ingeniería Sanitaria y Ambiental, 2006. p. 1-9.

CATANI, R. A; ALONSO, O. Avaliação da exigência de calcário do solo. Anais da Escola Superior de Agricultura "Luiz de Queiroz", Piracicaba, v. 26, n. 141, p. 156, 1969.

COMPANHIA ENERGÉTICA DE SÃO PAULO. Ilha Solteira: a cidade e a usina. São Paulo: CESP, 1988. 93 p.

CORDEIRO, G. C.; TOLEDO FILHO, R. D.; FAIRBAIRN, E. M. R. Caracterização de cinza do bagaço de cana-de-açúcar para emprego como pozolana em materiais cimentícios. Química Nova, São Paulo, v. 32, n. 1, p. 82-86, 2009.

CORREAA, R. S. Recuperação de áreas degradadas pela mineração no Cerrado: manual para revegetação. Brasília: Universa, 2005. 187 p.

CORREIA, J. R.; REATTO, A.; SPERA, S. T. Solos e suas relações com o uso e o manejo. In: SOUSA, D. M. G.; LOBATO, E. Cerrado: correção do solo e adubação. Planaltina: EMBRAPA Cerrados, 2002. p. 29-61.

CRESTANA, M. S. M.; FERRETTI, A. R.; TOLETO FILHO, D. V. Espécies arbóreas nativas do Estado de São Paulo recomendadas para reflorestamentos. In: CRESTANA, M. S. M.; FERRETTI, A. R.; TOLETO FILHO, D. V. Florestas: sistemas de recuperação com essências nativas, produção de mudas e legislação. São Paulo: Imprensa oficial, 2006. p. 49-84.

DURIGAN, G. Técnicas silviculturais aplicadas à restauração de ecossistemas. In: SIMPÓSIO SOBRE RESTAURAÇÃO ECOLÓGICA DE ECOSSISTEMAS NATURAIS, 1., 1999. Anais... Piracicaba: IPEF, 1999.

EMBRAPA. Centro Nacional de Pesquisa de Solos. Manual de métodos de análises de solo. 2. ed. Rio de Janeiro: EMBRAPA/CNPS, 1997. 212 p. (Documentos, 1).

ENGEL, V. L.; PARROTA, J. A. Definindo a restauração ecológica: tendências e perspectivas mundiais. In: KAGEYAMA, P. Y. et al. Restauração ecológica de ecossistemas naturais. Botucatu: FEPAF, 2003. p. 1-26.

FEITOSA, D. G.; MALTONI, K. L.; SILVA, I. P. F. Avaliação da cinza, oriunda da queima do bagaço da cana de açúcar, na substituição da adubação química convencional para produção de alimentos e preservação do meio ambiente. Revista Brasileira de Agroecologia, Porto Alegre, v. 4, p. 2412-2415, 2009.

FERREIRA, D. F. Análises estatísticas por meio do Sisvar para Windows versão 4.0. In: REUNIÃO 
ANUAL DA REGIÃO BRASILEIRA DA SOCIEDADE INTERNACIONAL DE BIOMETRIA, 45., 2000, São Carlos. Anais... São Carlos: UFSCar, 2000. p. 255-258.

FEDERAÇÃO DAS INDÚSTRIAS DO ESTADO DE SÃO PAULO. Ampliação da oferta de energia através da biomassa. São Paulo: FIESP/CIESP, 2001. Disponível em: <http://www.fiesp. com.br/publicacoes/pdf/ambiente/relatorio_dma.pdf $>$. Acesso em: 2 mar. 2009.

FONTES, M. P. F.; WEED, S. B. Phosphate adsorption y clays from Brazilian Oxisoils: relationships whit specific surface area and mineralogy. Geoderma, Amsterdam, v. 72, p. 377-51, 1996.

FREITAS, E. S. Caracterização da cinza do bagaço da cana-de-açúcar do município de campos dos goytacazes para uso na construção civil. 2005. $81 \mathrm{f}$. Dissertação (Mestrado) - Universidade Estadual do Norte Fluminense Darcy Ribeiro, Campo Dos Goytacazes, 2005.

GOMES, T. C. A. Análise de trilha no estudo de fatores físicos e químicos relacionados ao adensamento e, ou, à compactação em dois solos do Norte de Minas Gerais. 1996. 105 f. Dissertação (Mestrado em Solos e Nutrição de Plantas) - Universidade Federal de Viçosa, Viçosa, 1996.

KER, J. C. et al. Adsorção de fósforo em alguns solos latossólicos: relação entre mineralogia e efeito da calagem. Revista Ceres, Viçosa, MG, v. 43. n. 246, p. 216-226, 1996.

LEITE, L. L.; MARTINS, C. R.; HARIDASAN, M. Efeitos da descompactação e da adubação do solo na revegetação espontânea de uma cascalheira no Parque Nacional de Brasília. In: SIMPÓSIO SUL-AMERICANO, 1.; SIMPÓSIO NACIONAL SOBRE RECUPERAÇÃO DE ÁREAS DEGRADADAS, 2., Foz do Iguaçu. Anais... Curitiba: UFPR/Fundação de Pesquisa Florestal do Paraná, 1994. p. 527-534.

LIPIEC, J.; STCPNIEWSKI, W. Effects of soil compaction and tillage systems on uptake and losses of nutrients. Soil \& Tillage Research, Amsterdam, v. 35, p. 37-52. 1995.

LORENZI, H. Árvores brasileiras: manual de identificação e cultivo de plantas arbóreas nativas do Brasil. 1. ed. Nova Odessa: Plantarum, 1992. v. 1, 368 p.

MALTONI, K. L. Estudo de compactação e/ou adensamento em subsuperfícies de latossolos sob diferentes usos. 1994. 139 f. Tese (Doutorado em Solos e Nutrição de Plantas) - Universidade Federal de Viçosa, Viçosa, 1994.

MANDAL, D. K.; KAR, S.; SHARMA, S. K. Effect of compactation on nitrogen mobility in coarse textured lateritic soil. Journal of the Indian Society of Soil Science, New Delhi, v. 38, n. 1, p. 145-147, 1990.

MAYER L. M. et al. Organic matter in small mesopores in sediments and soil. Geochimica et Cosmochimica Acta, Oxford, v. 68, p. 3863-3872, 2004.

MCCARTHY, J. F. et al. Protection of organic carbon in soil microaggregates via restructuring of aggregate porosity and filling of pores with accumulating organic matter. Geochimica et Cosmochimica Acta, Oxford, v. 72, p. 4725-4744. 2008.

MEDEIROS, R. D.; SOARES, A. A.; GUIMARÃES, R. M. Compactação do solo e manejo da água I: efeitos sobre a absorção de N, P, K, Massa seca de raízes e parte aérea de plantas de arroz. Ciência e Agrotecnologia, Lavras, v. 29, n. 5, p. 940-947, 2005.

MELO, J. T. et al. Coleta, propagação e desenvolvimento inicial de espécies do Cerrado. In: SANO, S. M.; ALMEIDA, S. P. (Eds.). Cerrado: ambiente e flora. Planaltina: EMBRAPA -CPAC, 1998. p. 193-243.

MIKOLA, J.; SØRENSEN, L. I.; KYTÖVIITA, M. M. Plant removal disturbance and replant mitigation effects on the abundance and diversity of low-arctic soil biota. Applied Soil Ecology, Amsterdam, v. 82, p. 82-92, 2014.

MODANIA, P. O.; VYAWAHAREB, M, R. Utilization of Bagasse Ash as a Partial Replacement of Fine Aggregate in Concrete. Procedia Engineering, Linz, v. 51, p. 25-29. 2013. 
MONIZ, A. C. Evolução de conceitos no estudo da gênese de solos. Revista Brasileira de Ciência do Solo, Viçosa, MG, v. 20, p. 349-362, 1996.

MOREIRA, P. R. Manejo do solo e recomposição da vegetação com vista à recuperação de áreas degradadas pela extração da bauxita, Poços de Caldas, MG. 2004. 139 f. Tese (Doutorado em Ciências Biológicas) - Universidade Estadual Paulista "Júlio de Mesquita Filho", Rio Claro, 2004.

NEVES, C. S. V. J. et al. Efeitos de substratos e recipientes utilizados na produção das mudas sobre a arquitetura do sistema radicular de árvores de acácia-negra. Revista Árvore, Viçosa, MG, v. 29, n. 6, p. 897-905, 2005.

OLIVEIRA, A. N. et al. Variações genéticas para características do sistema radicular de mudas de baru (Dipteryx alata Vog). Revista Árvore, Viçosa, MG, v. 30, n. 6, p. 905-909, 2006.

OLIVEIRA, J. B.; JACOMINE, P. K. T.; CAMARGO, M. N. Classes gerais de solos do Brasil: guia auxiliar de reconhecimento. 2. ed. Jaboticabal: FUNEP, 1992. 102 p.

OLIVEIRA, T. S. Efeitos dos ciclos de umedecimento e secagem sobre propriedades físicas e químicas de quatro latossolos brasileiros. 1994. 104 f. Dissertação (Mestrado em Fitotecnia) Universidade Federal de Viçosa, Viçosa, 1994.

PAYÁ, J. et al. Sugar-cane bagasse ash (SCBA): studies on its properties for reusing in concrete production. Journal of Chemical Technology and Biotechnology, Chichester, v. 77, p. 321-325, 2002.

PITA, P. V. V. Valorização agrícola de cinza da co-combustão de bagaço de cana-de-açúcar e biomassa lenhosa. Lisboa, 2009. 80 f. Dissertação (Mestrado) - Universidade Técnica de Lisboa/ Instituto Superior de Agronomia, Lisboa, 2009.

PREVITALI, R. Z. Crescimento de mudas de pupunheira (Bactris gasipaes Kunth) em substrato compactado. 2007. 87 f. Dissertação (Mestrado) - Instituto Agronômico de Campinas, Campinas, 2007.

RAIJ, B. V. et al. Análise química para avaliação da fertilidade de Solos tropicais. Campinas: Instituto Agronômico, 2001. 285 p.

REIS, G. G. et al. Crescimento de Eucalyptus camaldulensis, E. grandis e E. cloeziana sob diferentes níveis de restrição radicular. Revista Árvore, Viçosa, MG, v. 13, n. 1, p. 1-18, 1989.

RESENDE, M. Mineralogy, chemistry, morphology and geomorphology of some soils of Central Plateau of Brazil. 1976. 237 f. Tese (Doutorado) - Purdue University, Lafayette, 1976.

RESENDE, M. et al. Pedologia: base para a distinção de ambientes. Viçosa: NEUPUT, 2002. V. $4,338 \mathrm{p}$.

RIBEIRO, J. F. et al. Baru (Dipteryx alata Vog.) Jaboticabal: Funep, 2000. 41 p.

RODRIGUES, G. B.; MALTONI, K. L.; CASSIOLATO, A. M. R. Dinâmica da regeneração do subsolo de áreas degradadas dentro do bioma Cerrado. Revista Brasileira de Engenharia Agrícola e Ambiental, Campina Grande, v. 11, n. 1, p. 73-80, 2007.

ROMERO, T. Bagaço na construção civil. São Paulo: Agência de Notícias da Fundação de Amparo à Pesquisa do Estado de São Paulo, 2007. Disponível em: <http://www.agencia.fapesp.br/ materia/7211/noticias/bagaco-na-construcaocivil>. Acesso em: abr. 2009.

RUIVO, M. L. P. Recuperação de áreas de mineração: uma experiência bem sucedida na Amazônia. In: FERREIRA, E. J. G. et al. (Eds.). Bases cientificas para estratégias de preservação e desenvolvimento da Amazônia. Manaus: INPA, 1993. p. 383-404.

SANO, S. M.; RIBEIRO, J. F.; BRITO, M. A. Baru: biologia e uso. Planaltina: Embrapa Cerrados, 2004. 52 p. (Documentos, 116).

SCHWERTMANN, U. Relations between iron oxides, soil color, and soil formation. In: BIGHAM, J. M.; CIOLKOSZ, E. J. (Eds). Soil color. Madison: Soil Science Society of America, 1993. 
p. 51-69. (Special publication, 31).

SHEPHERD, K. R. Plantation silviculture. Dordrecht: Martinus Nijhoff, 1986. 322 p.

SILVA, M. S. L. Caracterização e gênese do adensamento subsuperficial em solos de tabuleiros do semi-árido do Nordeste do Brasil. 2000. 126 f. Tese (Doutorado em Ciência do Solo) Universidade Federal do Rio Grande do Sul, Porto Alegre, 2000.

SOUSA-SILVA, J. C.; FAGG, C. W. Viveiros: produção de mudas nativas do bioma Cerrado. In: FAGG, C. W.; MUNHOZ, C. B. R.; SOUSA-SILVA, J. C. Conservação de áreas de preservação permanente do Cerrado. Brasília: CRAD, 2011. p. 115-146.

STITT, R. E.; CASSEL, D. K.; WEED, S. B. Mechanical impedance of tillage pans in Atlantic coastal plains soils and relationships with soil physical, chemical and mineralogical properties. Soil Science Society of America Journal, Madison, v. 46, p. 100-106, 1982.

TAVARES FILHO, J.; BARBOSA, G. M. Resistência à penetração e desenvolvimento do sistema radicular do milho (Zea mays) sob diferentes sistemas de manejo em um Latossolo Roxo. Revista Brasileira de Ciência do Solo, Viçosa, MG, v. 25, p. 725-730, 2001.

THIND, H. S. et al. Land application of rice husk ash, bagasse ash and coal fly ash: Effects on crop productivity and nutrient uptake in rice-wheat system on an alkaline loamy sand. Field Crops Research, Amsterdam, v. 135, p. 137-144, 2012.

VALCARCEL, R.; D’ALTERIO, C. F. V. Medidas fisicobiológicas de recuperação de áreas degradadas: Avaliação das modificações edáficas e fitossociológicas. Revista Floresta e Ambiente, Rio de Janeiro, v. 5, p. 68-88, 1998.

VASCONCELOS, V. F.; SANTOS, R. J. A. chegada do projeto Prodecer-I em Irai de Minas e os migrantes. In: SIMPÓSIO REGIONAL DE GEOGRAFIA, 2., 2003, Uberlândia. Anais... Uberlândia: UFUB, 2003. 15 p. Disponível em: <http://www.ig.ufub.br/2srg/1/1-121A.pdf.>. Acesso em: 6 fev. 2010. 